\title{
Analysis of Large-area Blackouts Caused by Errors in Rainfall Bombs
}

\author{
Xu Jianchun ${ }^{1}$, Su Hainan", Jiang Ling ${ }^{1}$, Xin Tian¹, Yue Yangzhuo², Shi Guodong ${ }^{2}$, Jin Jingxin ${ }^{1}$, \\ Song Xiaodong ${ }^{1}$, Shan $\mathrm{Jia}^{2}$, Zhang Mengzi ${ }^{1}$
}

1. Dandong Power Supply Company, Liaoning Electric Power Company Limited, State Grid, China

2. Fushun Power Supply Company, Liaoning Electric Power Company Limited, State Grid, China.

Keywords: Artificial rain. Silver iodide. Surface discharge. Pollution flashover.

\begin{abstract}
On March 12, 2017, in the Qingyishan area of Dandong City, a number of multi-point accidents with similar accidents occurred in a short period of time. Through the accident investigation, it was found that white powder adhered to the surface of the failed power equipment. After the accident, the white powder of the equipment was test and the test results showed that these white powders were the catalyst silver iodide particles of the shell. It was demonstrated that the rain-enhanced artillery shell did not explode at the designated altitude, and conductive silver iodide did not sufficiently fall down due to the action of the cumulonimbus cloud, and it was attached to the surface of the electrical equipment, causing the insulation resistance of the equipment to drop, resulting in phase-to-ground flashover discharge of the equipment. Through the investigation and analysis of the accident, this paper, on the basis of facts, expounds the failure of artificial precipitation, which the pollution flashover accident of the bare electrical equipment on the ground will be triggered and specific precautions will be put forward.
\end{abstract}

\section{Introduction}

Artificial precipitation is to use the physics of clouds, the catalysts (salt powder, dry ice, or silver iodide, etc.) are broadcast to the clouds by certain means of technology to the clouds, and the effect of artificial catalysis on the microphysical processes of clouds in the local on the microphysical processes of clouds in the local atmosphere is made to develop in the direction of people's expectations, so as to achieve the goal of seeking advantages and avoiding harm. It includes artificial precipitation, artificial hail suppression, artificial cloud elimination, artificial fog dispersal, and artificial precipitation is the most widely used.

Silver iodide is a commonly used catalyst. The shell containing silver iodide is injected into the air at a height of 4,000 to 5,000 meters so as to be dispersed in the cumulonimbus layer to form the condensed core of the water droplets in the cloud (ice core). The water droplets quickly condense around them to reach a certain volume and then land. Compared with the huge water droplets, the silver iodide in the upper air is just a drop in the sea. If the area is a previously unmanned area, people or objects will not be harmed.

The artificial precipitation enhancement and hail suppression operations of antiaircraft artillery were launched in 1950s in Liaoning. In 1991, the operation of artificial precipitation enhancement was formally carried out. More than 20 thousand rounds of ammunition are launched each year, with an average annual increase of precipitation is 1 billion 200 million cubic meters for Liaoning. Up to now, 54 sets of rocket rain enhancement systems, more than 360 antiaircraft guns and 3 fixed aircraft had been established in the whole province, so as to achieve very good rain enhancement effect.

\section{Mistakes in Artificial Rain Shells}

Artificial precipitation has a long history, and the technology is more mature. In general, artificial rain increase is safe. But artificial precipitation is complex system engineering and a lot of links are involved. If handled improperly, many problems have come into being, and the rate of error is around 3 per thousand. It is unavoidable to make mistakes in artificial rain. For example, 
around 17 o'clock in July 14, 2013, Liu Xiulin, a 57 years old woman in Liujia village, Kuandian County, was sitting around the stove with her family for dinner. First they heard a loud noise above their heads, and then something came down from the sky, through the roof and hit the floor of the house with a thud. This was a warhead as big as a fist. In order to artificially increase rainfall, an artificial rain bomb was launched into this area by Kuandian County Meteorological Bureau. Impartiality, the warhead dropped off from the shell and landed at the Liu family.

\section{Accidents}

At 22:10 on March 12, 2017, moderate rain occurred in the Dandong area, and around 22:40, a large area and multiple discharge breakdown accidents occurred in the $10 \mathrm{kV}$ distribution network of the Kuandian Power Supply Company. The fault points were widely distributed in the East Street of the Tianhua mountain road, the East Street of the street of the street, the West Street of the East Ring Road in the west, the left Zi Yuan Street in the South and the Ruan Chang Yuan Street in the north. There were 10 fault lines and 34 fault points. Kuandian town government, Central Hospital, West Gate Primary School, long distance passenger station, new century commercial city, 1\# East ring road opening and closing station, $3 \#$ West Ring Road opening and closing were the main users which were involved by this accident.

Because most of the lines in Dandong are double back, also there are four back ones. As long as one of the lines fails, other lines will also be affected, resulting in the blackout area being extended and the power failure time prolonged. During the emergency repair process, 31 lines were blackout at the same time, resulting in blackout processing time last from 22:00, 12th until 10:00, 13th, and 41 repair personnel and 12 vehicles had been used. All of these resulted direct and indirect economic losses. Failure statistics are shown in Table I

Table I Fault statistics table

\begin{tabular}{|c|c|c|c|c|c|c|}
\hline Name & $\begin{array}{l}\text { Drop } \\
\text { type }\end{array}$ & Switch & $\begin{array}{c}\text { Insulating } \\
\text { switch } \\
\end{array}$ & $\begin{array}{c}\text { Drainage } \\
\text { line }\end{array}$ & Trunk line & Accident nature \\
\hline Lishu line & 1 & & 10 & 2 & & $\begin{array}{l}\text { Three phase short } \\
\text { circuit }\end{array}$ \\
\hline $\begin{array}{l}\text { Sandaogou } \\
\text { line }\end{array}$ & & & & & 1 & $\begin{array}{c}\text { Three phase short } \\
\text { circuit }\end{array}$ \\
\hline Qingling line & 4 & 1 & 1 & 1 & & Two phase short circuit \\
\hline Taiping line & 2 & 1 & & & & Two phase short circuit \\
\hline Yuanqujia line & 1 & & & & & $\begin{array}{l}\text { Single-phase arc } \\
\text { grounding }\end{array}$ \\
\hline Yuanquyi line & 1 & & & 1 & & Two phase short circuit \\
\hline Liujia line & 1 & & & & & $\begin{array}{l}\text { Three phase short } \\
\text { circuit }\end{array}$ \\
\hline Jinyou line & 1 & 1 & & & & Two phase short circuit \\
\hline Dantie line & 1 & & & 1 & & Two phase short circuit \\
\hline Jinmeng line & 2 & 1 & & & & Two phase short circuit \\
\hline
\end{tabular}

\section{Accident Analysis}

\subsection{Accident characteristics}

From the above 10 lines, a lot of similarities are clearly seen in a total of 34 fault points statistics. Most of the accident points are concentrated on the lead wire of main line and the equipment involved in the lead wire. For example, the distribution transformer plate, the drop switch on the cable rack, the switch leads and so on. Most of accidents are phase-to-ground flashover, and the fault properties, forms, categories and severity of the failure of the electrical equipment are surprisingly similar whether they are newly installed (replace) or old lines.

The test results show that the overall performance of electrical equipment such as breaker, drop 
switch, isolation switch and so on is the reduction of surface insulation resistance, most of the drop switch fixed iron hoops are burned, the circuit breaker falls off directly(there are three things like this), the failure of lead wire (the main line leads are 240 square millimeter insulation lines) is mostly caused by two phase or three phase collapse or interruption, wire and upper rod head or transverse load disruptive discharge. And the scope of the accident is spread around the Qingyishan area. After statistics, 10 lines and 34 fault points are concentrated in the area of 8 square kilometers. The figure is shown in Figure 1

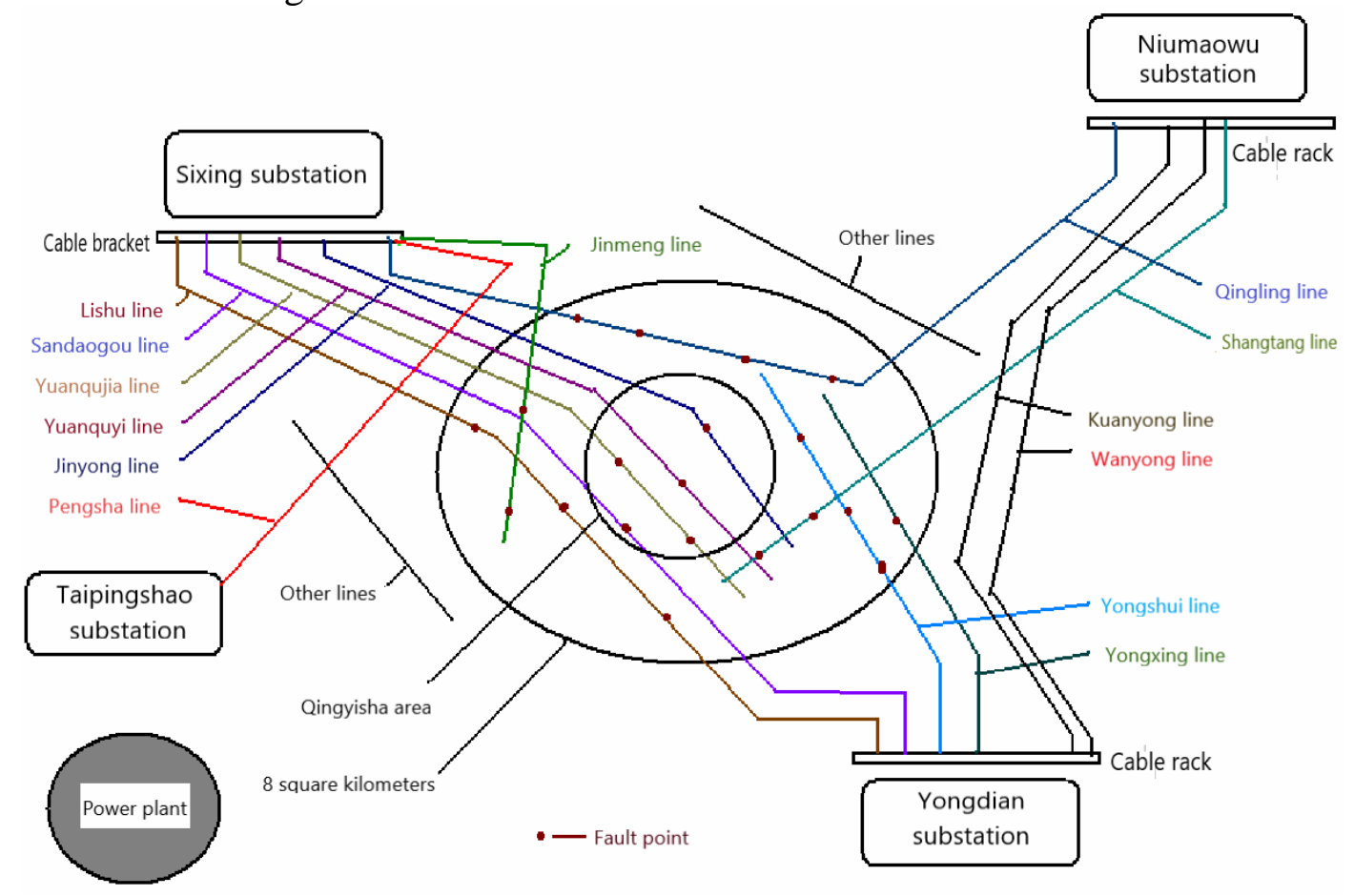

Fig. 1. Image map of accident area

\subsection{Expelled external cause}

It can be clearly seen from Figure 1 that the failure point of the accident is very concentrated and has never happened before. It is difficult to determine the cause of the accident for a time. Usually, there are 3 main reasons for large area blackout accident.

4.2.1. The insulation of the equipment is aging. In Figure 1. Multiple lines with regional concentration and different conditions, multiple points, and multiple equipment had similar faults at the same time, while the proximate Kuanyong line and Pengsha line which were more old and old could run safely, proving that the insulation aging was not caused by the internal insulation of the equipment.

4.2.2. Overvoltage has occurred. There was no thunder on that day, and lightning overvoltage could be excluded. If it was caused by resonance or overvoltage, it should be a single circuit or associated circuit. It could be clearly seen from Figure 1 that there was no correlation between fault lines and no lightning arrester was damaged, so it was not caused by overvoltage.

4.2.3. Pollution flashover. Some people suspect that the gray white powder was a dust from the power plant, but it was quickly denied because the dust could not fly around in the rainy day, and it was southwest but the fault point was located in the southeast direction of the power plant (it was southeast wind direction, and the fault point was located in the northeast direction of the power plant). Therefore, it was not a pollution flashover caused by dust.

In short, the large-scale blackouts were not caused by insulation aging or over voltage or pollution flashover

\subsection{Small grey and white particles were found on the surface of the device}

After denying the above 3 external causes, the replacement of the electrical equipment was further examined carefully, so as to further identify the cause of the accident. It was found that 
circuit breaker, isolating switch, falling fuse tube and lead wire had a common characteristic of change, that was, the surface was attached with unidentified What was the gray powdery foreign matter and where it come from are to be explored by electric workers. The comparison test of the equipment was made to determine whether the powdered foreign matter was conductive particles. The test results of insulation resistance and tolerance of ash powder on the surface of equipment are shown in Figure II.

Table II Insulation resistances and tolerance test of ash powder on the surface of equipment

\begin{tabular}{|c|c|c|c|c|}
\hline \multirow{2}{*}{ The name of the trial product } & \multicolumn{2}{|c|}{$\begin{array}{c}\text { The surface of the equipment is grayish } \\
\text { white powder }\end{array}$} & \multicolumn{2}{|c|}{$\begin{array}{c}\text { Remove gray white powder particles from the } \\
\text { surface of the equipment }\end{array}$} \\
\hline & $\begin{array}{c}\text { Insulation } \\
\text { resistance }(\mathrm{M} \Omega)\end{array}$ & $38 \mathrm{kV}$ voltage test & $\begin{array}{c}\text { Insulation } \\
\text { resistance }(\mathrm{M} \Omega)\end{array}$ & $38 \mathrm{kV}$ voltage test \\
\hline Lishu line(Circuit breaker) & 20 & Not pass & 10000 & Pass \\
\hline Sandaogou line(Circuit breaker) & 10 & Not pass & 9000 & Pass \\
\hline Qingling line(Circuit breaker) & 30 & Not pass & 10000 & Pass \\
\hline Taiping line(Isolating switch) & 10 & Not pass & 10000 & Pass \\
\hline Yuanqujia line(Isolating switch) & 10 & Not pass & 9000 & Pass \\
\hline Yuanquyi line(Isolating switch) & 20 & Not pass & 9000 & Pass \\
\hline Liujia line(Isolating switch) & 10 & Not pass & 10000 & Pass \\
\hline Jinyou line(Circuit breaker) & 20 & Not pass & 10000 & Pass \\
\hline Dantie line(Circuit breaker) & 30 & Not pass & 10000 & Pass \\
\hline Jinmeng line(Circuit breaker) & 20 & Not pass & 9000 & Pass \\
\hline
\end{tabular}

By measuring, the insulation resistance is related to the amount of gray powder particles covered. After surface gray white particles are completely removed, the insulation recovery and the $38 \mathrm{kV}$ tolerance test passed, which proved that the gray white powder is the conductive material, which is the root of the reduction of insulation resistance on the surface of electrical equipment.

The day after the accident, March $14^{\text {th }}$, the news of artificial precipitation was released by the Dandong daily, entitled "City Meteorological Bureau Increases Small to Moderate Rain for Our City by Rocket.” The report said that from 21:00 on March 12th to 2:00 on the 13th. 3 sets of rocket launchers were dispatched by the city's meteorological department. There were 14 people carried out large-scale artificial precipitation operations in Bahechuan Town, Maodianzi village and Shihugou Township respectively in a rainy day. A total of 18 silver iodide rockets were launched.

By consulting the data of artificial precipitation, the scientific principle and operation process of artificial precipitation are understood. And the time of artificial precipitation operation coincides with the time of accident. It can be affirmed that the accident of distribution lines and equipment centered on Qingyishan in the area of nearly 8 square kilometers is caused by artificial precipitation.

\subsection{Preliminary determination of the cause}

The area of this artificial precipitation should be over the Tianqiaogou area of Kuandian County, which was calculated in advance. Because of the mistake, it exploded 2000 meters above the Qingyishan area. Silver iodide itself was a charged colloidal particle. When the transmission error was made, silver iodide was scattered at a height below 2000 meters. Because there were no cumulonimbus clouds around them to function, the density in the air would be relatively large. If it was scattered in the denser areas of the electric power lines on the ground, the silver iodide was covered by the surface of the electrical equipment, which would lead to the surface discharge of the electrical equipment, causing the breakdown of electrical equipment. It is concluded that the grey and white particles of the surface of the electrical equipment should be silver iodide colloidal particles 


\section{Test confirmation}

\subsection{Inspection and confirmation of the Environmental Protection Bureau}

After the accident, after the accident, grey and white particles are cleaned in time by field workers. After being checked by Dandong Environmental Protection Bureau, it is determined that the main chemical component of this small gray particle is silver iodide.

\subsection{Identification of salt density and ash density test}

The part of the electrical equipment replaced in the accident area and the electrical equipment adjacent to the accident area will be taken a strict contrast test. The experimental data are shown in Table III.

Table III Test results of salt density and ash density of insulators in accident area

\begin{tabular}{ccccc}
\hline \hline $\begin{array}{c}\text { The provenance of the } \\
\text { tested product }\end{array}$ & Salt density & Ash density & $\begin{array}{c}\text { Pollution } \\
\text { level }\end{array}$ & Time of delivery \\
\hline Taiping line & 1.6501 & 7.932 & $\mathrm{e}$ & 2001 \\
\hline Qingling line & 1.7605 & 8.247 & $\mathrm{e}$ & 1999 \\
\hline Jinmeng line & 1.6498 & 7.755 & $\mathrm{e}$ & 2004 \\
\hline Yongzhen line & 0.4277 & 2.481 & $\mathrm{~d}$ & 1993 \\
\hline Kuanyong line & 0.3851 & 2.27 & $\mathrm{~d}$ & 2002 \\
\hline Pengsha line & 0.3483 & 1.877 & $\mathrm{~d}$ & 2002 \\
\hline \hline
\end{tabular}

In Table III, the level of contamination in the accident area has reached the "e" level, while the level of contamination adjacent to the accident area still belongs to the "d" level, which shows that the amount of conductive material on the surfaces of the electrical equipment in the accident area is more than outside the accident area.

\subsection{Verification of pollution flashover test}

To illustrate the problem, the drop switches, adjacent drop off switches and new drop switches in the accident area are compared. Tests are conducted at $45 \%$ (natural state) humidity and $90 \%$ humidity respectively for insulation resistance and pressure resistance test. The results are shown in Table IV.

Table IV

\begin{tabular}{ccccc}
\hline \hline Name & $\begin{array}{c}\text { Insulation resistance } \\
(\mathrm{M} \Omega)\end{array}$ & $\begin{array}{c}\text { Surface Discharge } \\
(\mathrm{kV})\end{array}$ & $\begin{array}{c}\text { Breakdown voltage } \\
(\mathrm{kV})\end{array}$ & $\begin{array}{c}\text { Humidity } \\
(\%)\end{array}$ \\
\hline $\begin{array}{c}\text { Drop } \\
\text { switch }\end{array}$ & 450 & 28 & 36 & 45 \\
\hline $\begin{array}{c}\text { Drop } \\
\text { switch }\end{array}$ & 10000 & 41 & 53 & 45 \\
\hline $\begin{array}{c}\text { Drop } \\
\text { switch }\end{array}$ & 30 & 5.6 & 11 & 90 \\
\hline \hline
\end{tabular}

From the values in Table IV, it can be seen that the small gray particles covered by the surface of the drop switch can greatly reduce the breakdown voltage. The small gray particles on the surface of electrical equipment are silver iodide. After the accident secretly glad, if this error silver iodide rain bomb hits in the upper part of the important substation, the economic loss and serious consequences will be unthinkable.

\section{Preventive Measure}

First, the power department should strengthen liaison with the meteorological department, increase publicity, explain the seriousness of the power accident, and arouse the consciousness of the whole society and the public on the protection of the power facilities. Secondly, equipment maintenance should be timely and preventive tests should be made regularly to ensure that the insulation of electrical equipment is good. The urban network is used to transform the opportunity, the distribution transformer plate is changed to the opening and closing station, and the overhead 
line is replaced by the electric cable with ring net cabinet to supply electricity. Third, it is necessary to try to cover insulation on the bare electrical equipment so as to raise the insulation level. For example, the insulating rubber is wrapped on the surface of the iron hoop, and composite insulators should be used in much polluted areas.

\section{Conclusion}

In response to the rain-increasing operation errors, major electrical discharge accidents have occurred in the catalyst release area. To avoid such accidents happening again, electric workers must understand and take measures.

1) When an artificial rain or snowfall exploded at a height of less than 2000 meters, if the powder of the undispersed viscous catalyst is covered on the insulator surface, it will cause phase-to-ground surface discharge, and may be further expanded to relative breakdown discharge, which will lead to a large area of blackout.

2) In case of heavy rain or snowfall, the silver iodide catalyst should be considered if there is a large, centralized blackout accident.

3) The power sector should promptly and actively communicate with the meteorological department and strengthen the cooperation between the two departments in related work. If artificial rain or snow falls accidentally, it will cause damage to electrical equipment. In related operations, every effort should be made to avoid damage to electrical equipment.

4) When artificial rain or snowfall, it must be complied with the relevant regulations for artificial rainfall and the location of fire should be chosen to stay away from the sky above the electrical equipment.

\section{References}

[1] Ma Guanqi. Artificial Weather Affected Sanqi Antiaircraft Gunpractice Teaching Material [M]. Beijing: Meteorological Press, 2014.

[2] Li Guangliang. Haze [M]. Beijing: Meteorological Press, 2002.

[3] Zhang Jing. Meteorological Science and Technology History [M]. Beijing: Science Press, 2012.

[4] Chen Tianxiang. Electrical test [M]. Beijing: China Electric Power Press, 2008.

[5] Yu Huayu, Xu Wencheng,Shen Gang. Anti-pollution flashing and live cleaning technology of high-voltage electrical equipment [M]. Beijing: China Electric Power Press 2006. 